r ScIDioc

\section{Investigation of Isolating of Human Mesenchymal Stem Cells From Umbilical Cord Blood and Labeling them with ${ }^{99 \mathrm{~m}}$ Technetium}

\section{International Journal of Stem Cell Research and Transplantation (IJST)} ISSN 2328-3548

S Abolhassani ${ }^{1}$, Yavari $\mathrm{K}^{2 *}$, Mohammadnejad J ${ }^{3}$

${ }^{1}$ Faculty of New Sciences and Technologies, University of Tehran, Tehran, Iran.

${ }^{2}$ Biotechnology lab, Nuclear Science and Technology Research Institute, (NSTRI), Atomic Nuclear Organization, Tehran, Iran.

${ }^{3}$ Department of Life Science Engineering, Faculty of New Sciences and Technologies, University of Tehran, Tehran, Iran.

\title{
Abstract
}

Tissue engineering through the imitation of nature has the ability to deal with the crisis caused by the shortage of donor organs and tissues. With regard to the ethical problems of extraction of embryonic stem cell, the present study investigated the isolation of mesenchymal stem cells from umbilical cord blood. Also investigated labeling of isolated stem cells with ${ }^{99 \mathrm{~m}}$ Technetium ( $\left.{ }^{99 \mathrm{~m}} \mathrm{TC}\right)$. In this research we explore the Ficoll density gradient method. Then to prove the isolated cells are multipotent, we differentiated them into adipocyte and osteocyte. Flow cytometric analysis of CD34 and CD38 was performed to examine the expression of these specific markers. After labeling the cells, the efficiency is measured by TLC papers and gamma counter. The results showed that the umbilical cord blood can be introduced as an appropriate cell source due to easy availability, low cost and no risk to mother or baby. The isolated stem cells have high potency of proliferating and differentiating. Also measurement of labeling efficiency at different times indicates high absorption of these cells. due to the difficulties in the isolation of adult stem cells from tissues; cord blood is a reliable alternative source.

Keywords: Cord Blood; Mesenchymal Stem Cell; ${ }^{99 \mathrm{~m}} \mathrm{TC}$.

\section{Introduction}

The human body response to injuries caused by illnesses, accidents or irregulars by aging is repairing, but in some serious cases, the power of healing is inadequate. Now there are two main problems in transplantation surgery. One is excess requirement for donor body parts, and the other is immunological matching between donator and recipient. Overcoming these problems needs a stem cell bank [1]. Tissue engineering through the imitation of nature has the ability to deal with the crisis caused by the shortage of donor organs and tissues. Physicians have treated some specific diseases using nourishment to minimize enemy agents and optimize the environment so that the body itself begins to heal. The same process occurs in tissue engineering at cellular scale. In fact, in tissue engineering, the living and efficient tissue is produced by means of vivid cells and a scaffold for orientation and spreading of tissue. Cell sources, including types of stem cells which have been identified in recent years, have stimulated many interests in this context [2]. Thing that makes these cells especial is their ability to renew and plasticity. They are capable of renewing themselves and also repairing and replacing of other tissues [3]. Despite the immense potential of embryonic stem cells, using of them is a controversial topic [4]. Issues and ethical dilemmas of embryonic stem cells results in the inability to access new sources of these cells. This problem stimulates researchers to investigate the ability of adult stem cells for tissues and organs repair [5]. Several studies have been done to investigate whether the umbilical cord blood (UCB) can be a source of multipotent mesenchymal stem cells (MSCs) or not. Several methods are used for induction of UC-MSCs differentiate into cells with different functions. After desired induction, result showed that these cells are capable of differentiation into cardiac muscle cells, neurons, osteocytes and adipocytes in appropriate conditions. Technetium- $99 \mathrm{~m}$ is a metastable nuclear isomer of technetium-99, its symbol is ${ }^{99 \mathrm{~m}} \mathrm{TC}$. It is used in many of medical diagnostic procedures annually. When it is used as a tracer can be detected in the body by gamma cameras. hMSCs ${ }^{99}$ TC labeling is suited for biodistribution studies. Because of the short half-life of ${ }^{99 \mathrm{~m}} \mathrm{TC}(6 \mathrm{~h})$ and its emission energy

\footnotetext{
*Corresponding Author:

Kamal Yavari,

Biotechnology lab, Nuclear Science and Technology Research Institute, (NSTRI), Atomic Nuclear Organization, North Kargar street, Tehran, Iran Email : yavari_kamal@yahoo.com
}

Received: August 02, 2016

Accepted: August 11, 2016

Published: August 17, 2016

Citation: S Abolhassani, Yavari K, Mohammadnejad J (2016) Investigation of Isolating of Human Mesenchymal Stem Cells from Umbilical Cord Blood and Labeling them with 99m Technetium. Int J Stem Cell Res Transplant. 04(6), 190-194. doi: http://dx.doi.org/10.19070/2328-3548-1600031

Copyright: Yavari $\mathbf{K}^{\circ}$ 2016. This is an open-access article distributed under the terms of the Creative Commons Attribution License, which permits unrestricted use, distribution and reproduction in any medium, provided the original author and source are credited. 
is fitted with gamma-cameras, thus certifying high image quality [6]. The half-life of this radioisotope is appropriate because it is long enough to examine metabolic process and also it is a short time for minimizing radiation to the body.

Thus with enough evidence, these cells can be considered as multipotent mesenchymal stem cells since they are capable of differentiation into three germ layers. These cells can be an alternative source for bone marrow mesenchymal stem cells.

\section{Materials and Methods}

\section{Samples Collection}

14 cord blood samples were collected from 3 different hospitals in Tehran, Iran. After birth and separation of the umbilical cord, the placenta is separated from the uterine wall and is removed. Approximately 50 to $150 \mathrm{ml}$ of blood is stored in it. Only a few minutes after birth, blood clots form in umbilical cord and placenta. Thus we only have 10 minutes time; otherwise stem cells should be discarded. The baby's umbilical cord blood is collected after complete detachment of umbilical cord and so there is no harm to the baby and mother. About 25 to 40 of blood collected in $50 \mathrm{ml}$ falcons in which there were $300 \mu \mathrm{l}$ of heparin to prevent blood clots. Transferring the samples from hospitals to the laboratory was done in the shortest possible time and for controlling the temperature we used dry ice.

\section{Isolating of Stem Cells}

First fresh heparinized blood placed into 50 conical centrifuge tubes and then by using a sterile pipet, an equal volume of room temperature PBS was added and mixed well. Then the blood/ PBS mixture which prepared in previous stage was slowly layered over the Ficoll solution (Baharafshan, Iran) in another centrifuge tube. At this stage, in order to optimize this process, different volume ratios of the blood/PBS mixture to Ficoll solution were tested. In volume ratios of mixture to Ficoll solution were 1:1, 2:1 and 3:1. Then it was centrifuged $30 \mathrm{~min}$ at $2000 \mathrm{rpm}, 19^{\circ} \mathrm{C}$, without any brake. At next stage by using a sterile pipet, the upper layer which contains the plasma and platelets was removed. Then by another sterile pipet, the cell layer was transferred to another centrifuge tube. Cells were washed by adding HBSS 3 times the volume of cell layer and centrifuged $10 \mathrm{~min}$ at $1300 \mathrm{rpm}$ and $19^{\circ} \mathrm{C}$. Supernatant was removed, cells were resuspended in HBSS, and repeated the washing once to remove most of plateles. At final stage the cell pellet were resuspended in complete DMEM containing 10\% FBS (Gibco, USA), transferred to a $25 \mathrm{~cm}^{2}$ tissue culture flask and placed in a $37^{\circ} \mathrm{C}, 5 \% \mathrm{CO}_{2}$ humidified incubator [7]. After 5 weeks, the colonies were formed. To investigate the multipotency of isolated cells, their differentiation into osteocytes and adipocytes were assessed. The cells were incubated in a 6 well plate containing osteocyte differentiation medium culture (Bio Idea Group, Iran) and adipocyte differentiation medium (Stemcell Technology, Iran) for 21 days. The medium was changed every 3 days. The potentiality of osteocyte differentiation was evaluated by Alizarin Red staining. Cells were washed with PBS and then fixed with methanol for $10 \mathrm{~min}$ at room temperature. For staining, first cells were washed with distillated water, then $2 \mathrm{ml}$ Alizarin Red was added for $5 \mathrm{~min}$ at room temperature. The stain was removed, washed with distillated water and the result observed by inverted microscope. The potentiality of adipocyte differentiation was evaluated by Oil Red O staining. The stages were the same as explained before with these differences: the fixation was with $4 \%$ paraformaldehyde for $30 \mathrm{~min}$, the stain was added for $15 \mathrm{~min}$ and the cells were washed with $70 \%$ ethanol (figure 4).

\section{hMSCs Labeling}

First the cells in $75 \mathrm{ml}$ T-flask were trypsinised and then washed with PBS 1X solution. After that they were centrifuged for $10 \mathrm{~min}$ at $5000 \mathrm{rpm}$. After centrifugation, supernatants were removed and cells were suspended in $\mathrm{Sncl}_{2}$ solution for $10 \mathrm{~min}$ at room temperature. To prepare $\mathrm{Sncl}_{2}$ solution, $120 \mu \mathrm{g}$ of $\mathrm{Sncl}_{2}$ was dissolved in $10 \mathrm{ml}$ distilled water. Then it was centrifuged for $5 \mathrm{~min}$ at $5000 \mathrm{rpm}$. At next stage, $7.1 \mathrm{mCi}$ of ${ }^{99 \mathrm{~m}} \mathrm{TC}$ was added to the cells at placed at room temperature for 10 minutes. Then centrifuged at $5000 \mathrm{rpm}$ for 5 minutes.

\section{Determination of Labeling Stability}

To determine the efficiency, we used thin-layer chromatography (TLC) at different times. For this purpose, normal saline was chose as the mobile phase and Whatman number 3 paper as the stationary phase. Sampling was in distance of $2 \mathrm{~cm}$ from the top of the paper. After drying the sample, the paper placed in normal saline. After the mobile phase passed approximately $5 \mathrm{~cm}$, the paper was dried, and finally the paper was divided into several areas and activity levels were determined using a gamma counter. Good outcomes have been obtained, they are shown in figure 5 .

\section{Results}

After isolating cells from umbilical cord blood, to confirm they are stem cells, we used several methods including: assessment of morphology of cells by optical microscope, analyzing of CD markers by flow cytometry, to assess the differentiation potential and multipotency of them, their ability to differentiate into mesenchymal lineages such as osteocyte and adipocyte were investigated.

\section{Morphology of HUC-MSCs}

The first step to confirm the nature of the isolated cells is morphology of them. The isolated cells were observed by inverted microscope. In Figure 1, cells are shown 3 days after second passage.

Due to inaccessibility of specific markers of mesenchymal stem cells, specific markers of hematopoietic stem cells, including CD34 and CD38 were used. As shown in figure 2, cord blood stem cells are negative for these markers. Previous findings by others also corroborate the negative expression of antigen CD34 [8-10].

\section{Results of mesenchymal stem cells cultured in differentia- tion medium}

Due to the lack of specific marker for mesenchymal stem cells, it is necessary to use other methods in addition to flow cytometric analysis. One way is to evaluate the strength of stem cells differentiation into different lineages. As it was explained in the previ- 
Figure 1. Morphology of isolated cells from umbilical cord blood, 3 days after second passage (magnification 100x).

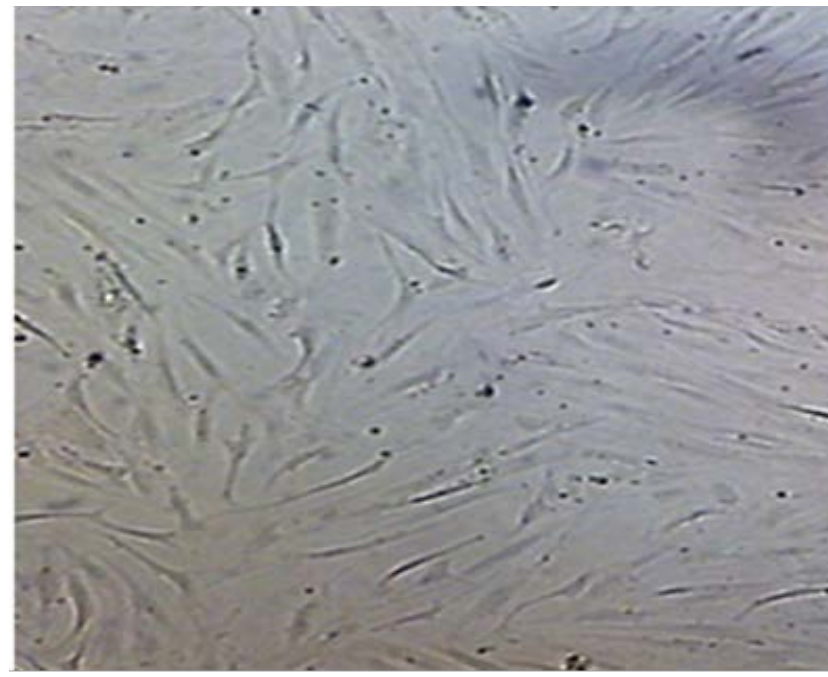

Figure 2. Flow cytometric analysis of UC-MSC cells.

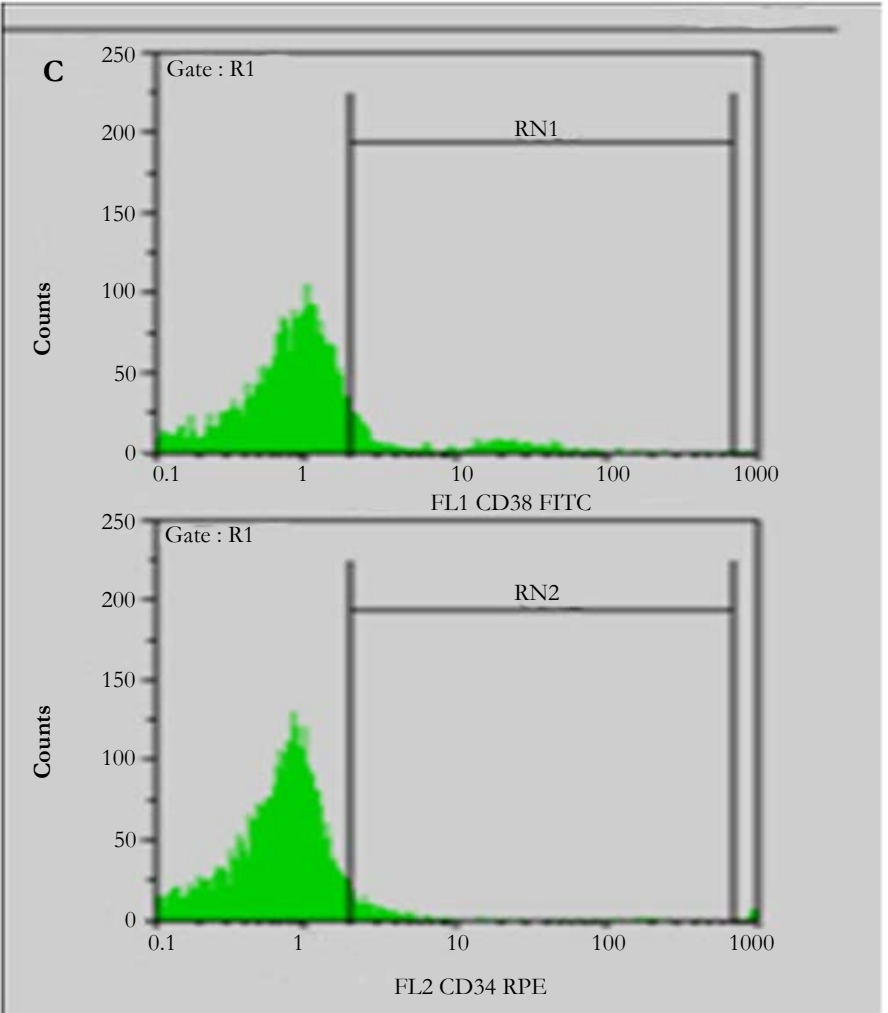

Figure3. The osteogenic differentiation of UC-MSCs after 3 weeks of treatment with osteocyte differentiation medium, stained with Alizarin Red, (A) control sample, (B) differentiated sample (magnification: 100x)
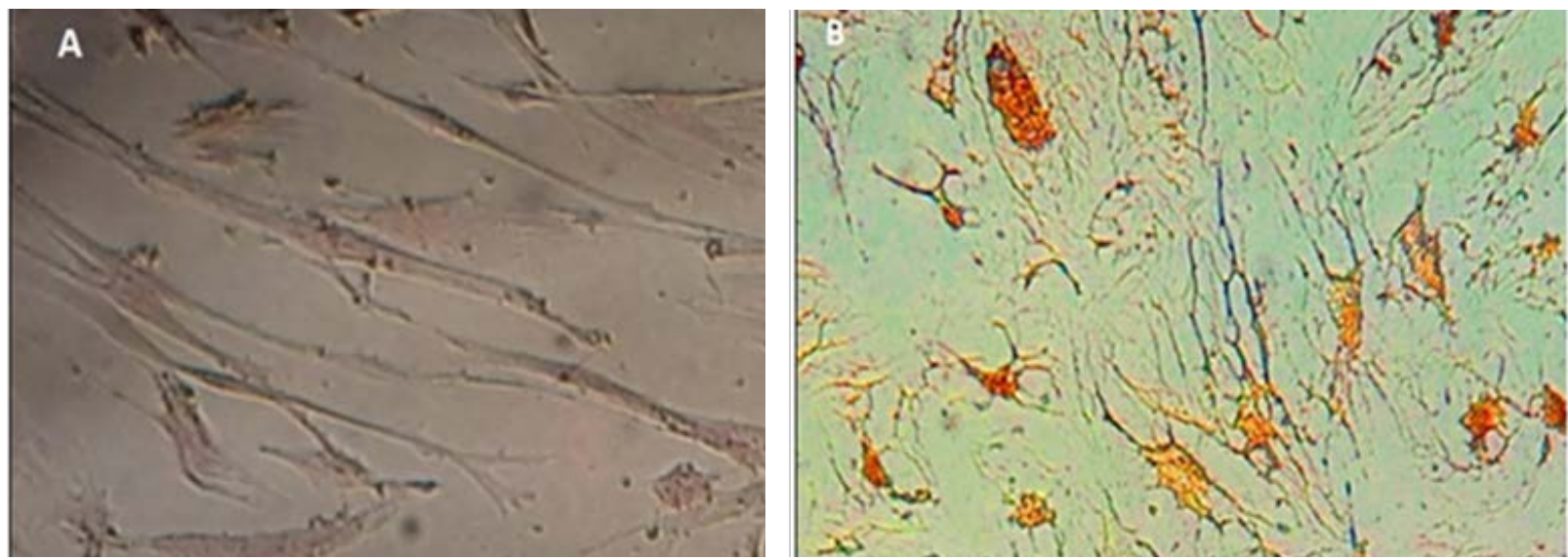
Figure 4. Adipogenic differentiation of UC-MSCs after 3 weeks of treatment with adipocye differentiation medium, stained with Oil Red O, (A) control sample, (B) differentiated sample (magnification: 100x)
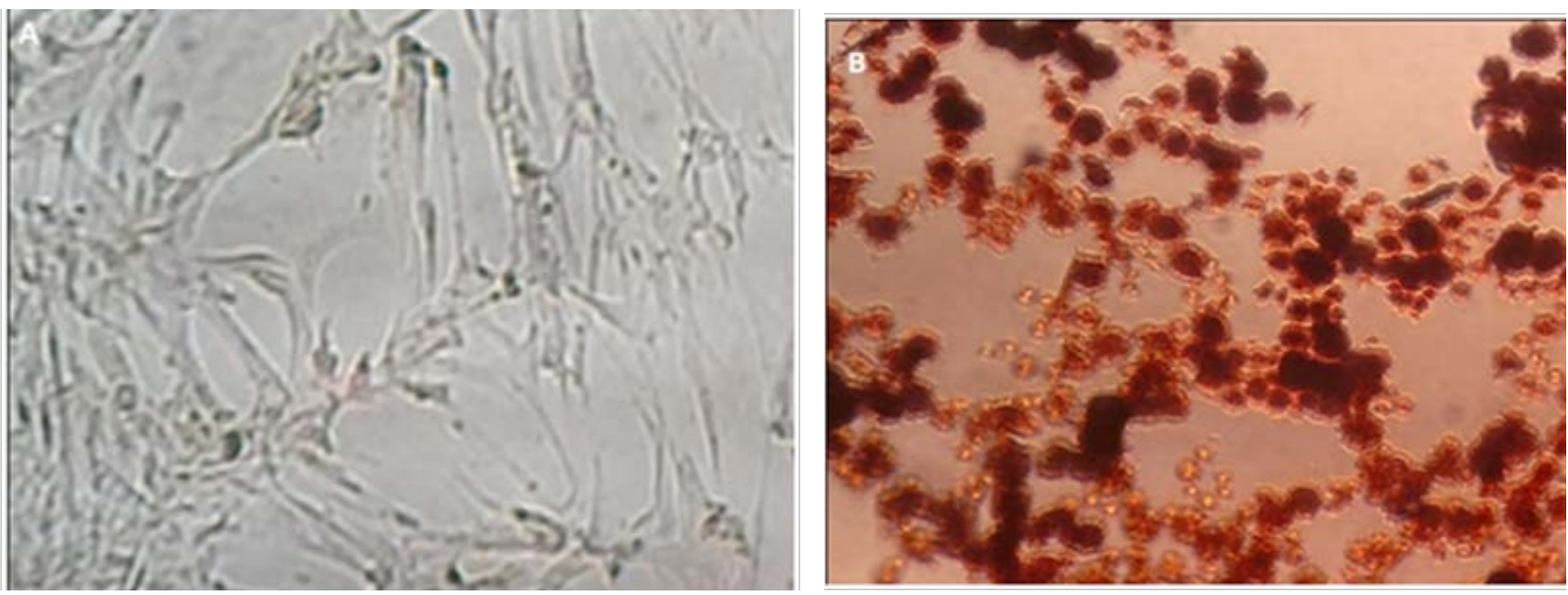

Figure 5. Stability of labeling of human cord blood mesenchymal stem cell with ${ }^{99 \mathrm{~m}} \mathrm{TC}$

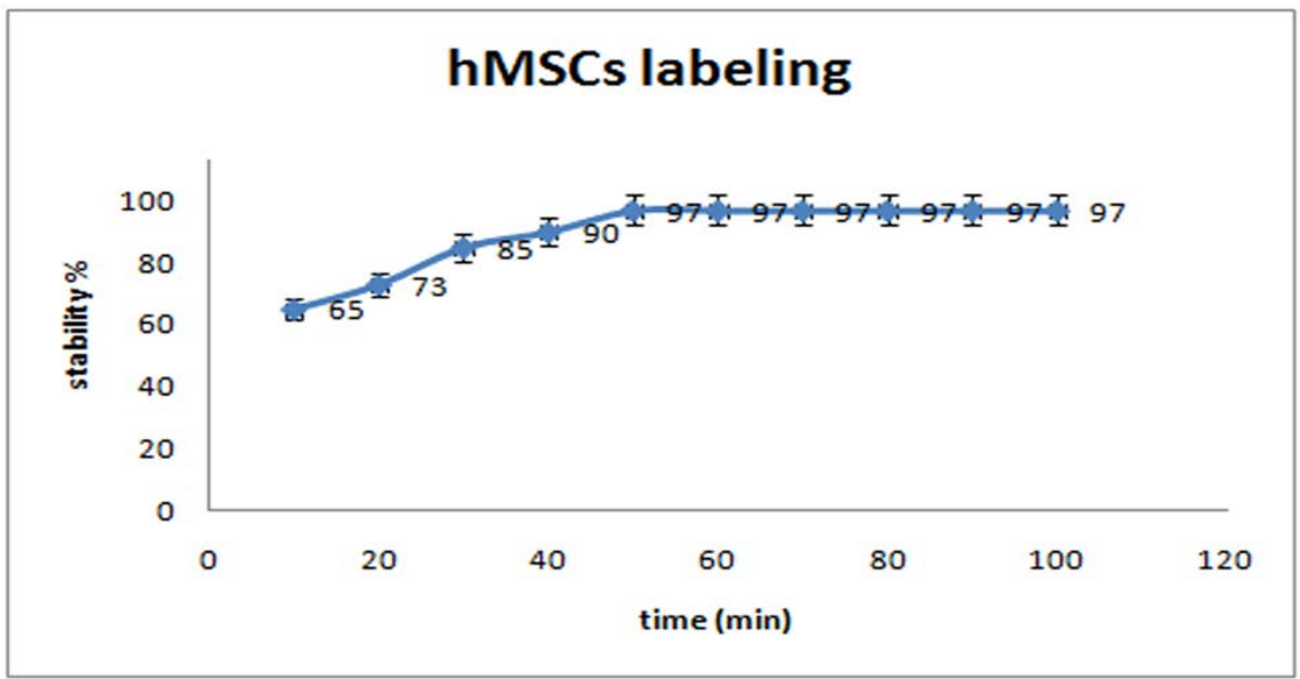

ous section, using proper differentiation mediums such as adipocyte differentiation and osteocyte differentiation medium, and the results were confirmed by appropriate staining. Results are shown in figures 3 and 4 .

\section{Discussion}

Cord blood samples older than $13 \mathrm{~h}$ don't show mesenchymal-like cells, this result is similar to what had been reported by Bierback et al [10]. The samples obtained from cord blood of newborns delivered by NVD had a greater number of cells compared to infants who were born by cesarean. In samples which we used equal volume ratio of Ficoll to blood/PBS mixture lead to the most dominant formation of layers.

As the figure 1 shows, the cells are elongated, spindle like and their morphology is similar to fibroblast cells. Morphology of isolated cells was in accordance with the UC-MSC cells reported by
Hua et al and Bierback et al $[8,10]$.

Using staining of lipids vacuoles by Oil Red $\mathrm{O}$, adipogenesis was confirmed also assessment of osteogenesis was by Alizarin Red staining. Figure 4B shows differentiated cells are well-stained, which results in the accumulation of calcium in bone cells. While the control sample was not stained due to lack of mineralization.

As the figure 5 shows, by passing time, the number of cells attached to ${ }^{99 \mathrm{~m}} \mathrm{TC}$, reached a maximum level at $50 \mathrm{~min}$. stability of a radioisotope is a considerable factor in labeling, because instability may lead to cell death.

\section{Conclusion}

The expected potential of mesenchymal stem cells is an issue of utmost importance in future therapeutic methods such as cell therapy. One considerable point is that the use of embryonic 
stem cells is rejected because of ethical issues and using stem cells which are derived from tissues may be not always acceptable because of a significant reduction in cell number and also large reduction in capability of proliferation/differentiation which are caused by increasing age. Thus cord blood could be an appropriate alternative source for mesenchymal stem cells and also has proven to be a proper source for hematopoietic stem cells.

\section{Acknowledgement}

This research was financially supported by Nuclear Science and Technology Research Institute of Iran (NSTRI).

\section{References}

[1]. Shard AG, Tomlins PE (2006) Biocompatibility and the efficacy of medical implants. Regen med 1(6): 789-800.

[2]. Lanza Robert, Langer Robert, Vacanti Joseph P ( 2011)Principles of tissue engineering. (3rd edn), Academic press.

[3]. To LB, Haylock DN, Simmons PJ, Juttner CA ( 1997) The biology and clinical uses of blood stem cells. Blood 89(7): 2233-2258.
[4]. Klimanskaya I, Chung Y, Becker S, Lu SJ, Lanza R ( 2006) Human embryonic stem cell lines derived from single blastomeres. Nature 444(7118): 481-485.

[5]. Hematti P1, Sloand EM, Carvallo CA, Albert MR, Yee CL, et al., (2002) Absence of donor-derived keratinocyte stem cells in skin tissues cultured from patients after mobilized peripheral blood hematopoietic stem cell transplantation. Exp hematol 30(8): 943-949.

[6]. Detante O, Moisan A, Dimastromatteo J, Richard MJ, Riou L, et al., ( 2009) Intravenous administration of $99 \mathrm{mTc}$-HMPAO-labeled human mesenchymal stem cells after stroke: in vivo imaging and biodistribution. Cell transplant 18(12): 1369-1379.

[7]. Kanof M, Smith P, Zola H ( 1991) Preparation of human mononuclear cell populations and subpopulations. Current protocols in immunology 2(19): $1-7$.

[8]. Jinlian Hua, Pubin Qiu, Haijing Zhu, Hui Cao, Fang Wang, et al., ( 2011) Multipotent mesenchymal stem cells (MSCs) from human umbilical cord: potential differentiation of germ cells. Afr J Biochem Res 5(4):113-23.

[9]. Sasaki M, Abe R, Fujita Y, Ando S, Inokuma D, et al., (2008) Mesenchymal stem cells are recruited into wounded skin and contribute to wound repair by transdifferentiation into multiple skin cell type. J immunol 180(4): 2581-2587.

[10]. Bieback K, Kern S, Klüter H ( 2004) Critical parameters for the isolation of mesenchymal stem cells from umbilical cord blood. Stem cells 22(4): 625634. 